Polymer Journal, Vol. 9, No. 4, 429-430 (1977)

SHORT COMMUNICATION

\title{
Synthesis of Polyamides from $N$-Malonic Diesters of Uracil and Theophylline
}

\author{
Koichi Kondo, Shigeo Miki, and Kiichi Takemoto \\ Department of Petrochemistry, Faculty of Engineering, \\ Osaka University, Suita 565, Japan.
}

(Received March 25, 1977)

\begin{abstract}
KEY WORDS Polyamides / Polycondensation / $N$-Malonic Diesters / Uracil / Theophylline / Diamines /
\end{abstract}

In order to prepare oligo- and polyamides of different types containing nucleic acid bases, (a) condensation of 9 -( $\beta$-carboxyethyl) adenine with triethylamine in dimethylformamide solution, ${ }^{1}$ and also (b) polymerization of amino acid $N$ carboxylic acid anhydrides containing purine and pyrimidine bases $^{2}$ have recently been studied, and thus the preparation of oligoamides having adenine both in the main chain and as side groups has been established.

The communication is concerned with the synthesis of diethyl malonates having uracil and theophylline bases, as well as their further polycondensation with diamines.

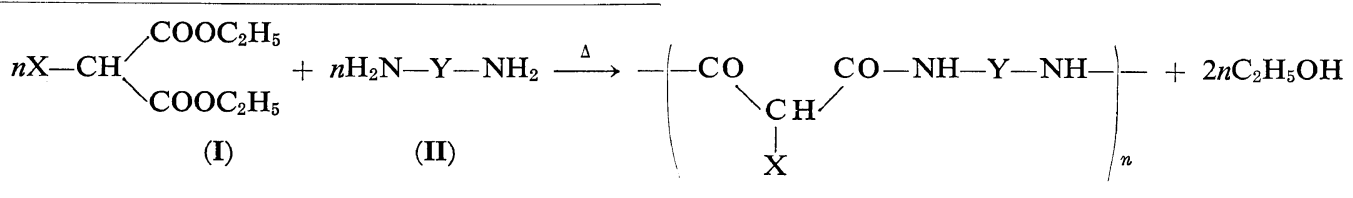

$\mathrm{X}$ :<smiles>Cn1ccc(=O)[nH]c1=O</smiles>

(Ia)<smiles></smiles>

(Ib)

Diethyl uracil-1-malonate (Ia) was prepared by the reaction of sodium salt of uracil with diethyl bromomalonate in dimethylformamide solution at room temperature, with a minor modification of the method by Nnadi and Wang. ${ }^{3}$ As an alternative method, the following one starting from 4-ethoxy-2-pyrimidone was also found recommendable. The reaction of the sodium salt of 4-ethoxy-2-pyrimidone (III) with diethyl bromomalonate was carried out at room temperature in the dimethylformamide solution, and the diethyl 4-ethoxy-2-pyrimidone-1-malonate(IV) obtained in a 59-\% yield was stirred with $1-N$ hydrochloric acid at room temperature to furnish Ia in a $85-\%$ yield:<smiles>CCOC(=O)C(Br)C(=O)OCC</smiles><smiles>CCOC(=O)C(C(=O)OCC)n1ccc(OCC)nc1=O</smiles> 
Diethyl theophylline-7-malonate (Ib) was prepared according to the method of Aliprandi and coworkers. ${ }^{4}$

The polycondensation of diethyl molonates containing uracil and theophylline was effected by the solution polymerization technique with diamines including 1,3-diaminopropane (DAP) and 1,6-diaminohexane (DAH). As an example, $0.81 \mathrm{~g}(3 \mathrm{mmol})$ of Ia and $0.245 \mathrm{~g}(3.3 \mathrm{mmol})$ of DAP were dissolved in $30 \mathrm{ml}$ of ethanol, and the solution was heated for $6 \mathrm{hr}$ at $130^{\circ} \mathrm{C}$ under a nitrogen stream. After cooling, ethanol was further added, and the resulting yellowish solid was filtered, washed thoroughly with ethanol and water, and dried. The yield amounted $0.625 \mathrm{~g}$ (70\%). The polymer melting at $200-208^{\circ} \mathrm{C}$ with decomposition was insoluble in common organic solvents, and showed with IR spectroscopy, as expected crosslinked polyamide structure.

In the case of polycondensation of diethyl malonate having a theophylline base with diamines, soluble polymers were obtained in a similar reaction condition. The yield was 60 and $40 \%$ for cases using DAP and DAH, respectively. The polymers begin to soften at about $200-220^{\circ} \mathrm{C}$, are soluble in water, dimethylformamide and dimethyl sulfoxide, and insoluble in alcohols. The molecular weight determined by vapor-pressure osmometry in dimethylformamide solution at $65^{\circ} \mathrm{C}$ was in a range of 1100 to 1200 , showing that the polymers obtained are rather oligomeric ones. Further study is now in progress.

\section{REFERENCES}

1. K. Kondo, M. Miyata, and K. Takemoto, Bull. Chem. Soc. Jpn., 44, 2554 (1971).

2. K. Takemoto, H. Tahara, A. Yamada, Y. Inaki, and N. Ueda, Makromol. Chem., 169, 327 (1973).

3. J. C. Nnadi and S. Y. Wang, J. Am. Chem. Soc., 92, 4421 (1970).

4. B. Aliprandi, F. Cacace, and G. Montefinale, Farmaco (Povia) Ed. Sci., 12, 751 (1957); C.A., 52, 11082 (1958). 